\title{
Aerosol optical depth (AOD) retrieval using simultaneous GOES-East and GOES-West reflected radiances over the western United States
}

\author{
H. Zhang ${ }^{1,2}$, R. M. Hoff ${ }^{1}$, S. Kondragunta ${ }^{3}$, I. Laszlo ${ }^{3}$, and A. Lyapustin ${ }^{4}$ \\ ${ }^{1}$ Joint Center for Earth Systems Technology (JCET), University of Maryland Baltimore County, Baltimore, MD, USA \\ ${ }^{2}$ I.M. Systems Group, College Park, MD, USA \\ ${ }^{3}$ NOAA/NESDIS/STAR, College Park, MD, USA \\ ${ }^{4}$ NASA/GSFC, Greenbelt, MD, USA \\ Correspondence to: H. Zhang (hai.zhang@noaa.gov)
}

Received: 13 October 2012 - Published in Atmos. Meas. Tech. Discuss.: 30 October 2012

Revised: 31 January 2013 - Accepted: 5 February 2013 - Published: 26 February 2013

\begin{abstract}
Aerosol optical depth (AOD) in the western United States is observed independently by both the (Geostationary Operational Environmental Satellites) GOES-East and GOES-West imagers. The GASP (GOES Aerosol/Smoke Product) aerosol optical depth retrieval algorithm treats each satellite as a unique sensor and thus obtains two separate aerosol optical depth values at the same time for the same location. The TOA (the top of the atmosphere) radiances and the associated derived optical depths can be quite different due to the different viewing geometries with large difference in solar-scattering angles. In order to fully exploit the simultaneous observations and generate consistent AOD retrievals from the two satellites, the authors develop a new "hybrid" aerosol optical depth retrieval algorithm that uses data from both satellites. The algorithm uses both GOESEast and GOES-West visible channel TOA reflectance and daily average AOD from GOES Multi-Angle Implementation of Atmospheric Correction (GOES-MAIAC) on low AOD days (AOD less than 0.3), when diurnal variation of AOD is low, to retrieve surface BRDF (Bidirectional Reflectance Distribution Function). The known BRDF shape is applied on subsequent days to retrieve BRDF and AOD. The algorithm is validated at three AERONET sites over the western US. The AOD retrieval accuracy from the "hybrid" technique using the two satellites is similar to that from one satellite over UCSB (University of California Santa Barbara) and Railroad Valley, Nevada. Improvement of the accuracy is observed at Boulder, Colorado. The correlation coefficients
\end{abstract}

between the GOES AOD and AERONET AOD are in the range of 0.67 to 0.81 . More than $74 \%$ of AOD retrievals are within the error of $\pm(0.05+0.15 \tau)$ compared to AERONET AOD. The hybrid algorithm has more data coverage compared to the single satellite retrievals over surfaces with high surface reflectance. For single observation areas the number of valid AOD data increases from the use of two-single satellite algorithms by $5-80 \%$ for the three sites. With the application of the new algorithm, consistent AOD retrievals and better retrieval coverages can be obtained using the data from the two GOES satellite imagers.

\section{Introduction}

Atmospheric aerosol is an important component of climate change and public health research. Aerosols radiatively "force" climate through the direct and several indirect effects (Charlson et al., 1992; Kiehl and Briegleb, 1993; Ramanathan et al., 2001; Lohmann and Feichter, 2005; IPCC, 2007). Aerosols affect public health and are regulated as a priority air quality pollutant (Pope and Dockery, 2006; Chow et al., 2006). The Environmental Protection Agency (EPA), state and local governments monitor $\mathrm{PM}_{2.5}$ (particulate matter with diameter less than $2.5 \mu \mathrm{m}$ ) through surface monitoring networks, available to the public at the AIRNOW site (http://airnow.gov). To fill the gaps between the surface stations, satellite retrieved aerosol properties such as aerosol 
optical depth (AOD) have been used as a proxy to the surface $\mathrm{PM}_{2.5}$ (e.g. Al-Saadi et al., 2005; Hoff and Christopher, 2009; Zhang et al., 2009).

AOD retrievals from the polar-orbiting satellite instrument MODIS (Moderate-Resolution Imaging Spectroradiometer; Kaufman et al., 1997; Levy et al., 2007) provide a global daily coverage but sparse temporal sampling (once a day at mid-latitudes). Geostationary satellites offer high frequency observations resolving the diurnal cycle. This helps monitor significant events, such as wildfire smoke emissions, enables observation of prior aerosol motion, and potentially enables forecasting aerosol motion through data assimilation techniques. The (Geostationary Operational Environmental Satellites) GOES-East and GOES-West imagers observe the continental United States (CONUS) every half hour (Prados et al., 2007). The Spinning Enhanced Visible and Infrared Imager (SEVIRI) onboard the Meteosat Second Generation (MSG) satellite takes images of European-African area every 15 min (Popp et al., 2007) and it also provides a rapid scan service with 5 min temporal resolution for a smaller area of Europe (EUMETSAT, 2013). The current GOES imagers, however, have only a limited number of channels in the short wavelength part of the spectrum, and therefore a multichannel algorithm like the one developed for MODIS cannot be applied. For the current GOES data, the GOES Aerosol/Smoke Product (GASP) was developed and has been operational at NOAA to monitor AOD over the United States (Knapp et al., 2002, 2005; Prados et al., 2007). A similar algorithm was also developed for SEVIRI in Europe (Popp et al., 2007).

GASP is applied independently to the two GOES satellites, GOES-East (currently GOES-13) at $75^{\circ} \mathrm{W}$, and GOESWest (currently GOES-15) at $135^{\circ} \mathrm{W}$. Figure 1a shows a schematic view of the solar-satellite geometries of the two satellites and Fig. 1b shows the scattering angles during a day. The two GASP products are independent and at some times during the day with large differences in scattering angles, the AOD retrievals for the two instruments can be quite different for the same surface location. In practice, the user is left to choose which geometry is likely to give a more precise result. Prior work limited extreme viewing geometries so that the best retrieval is produced from the two algorithms, but even so there can be conflicting results. The quality assurance technique by which a combined answer from the two satellites is termed a "combined retrieval". It should be possible, however, to add additional information from the TOA reflectances from the two satellites, a "hybrid retrieval", by giving additional degrees of freedom in the solution for AOD. This paper examines that option. It should be noted that to do so, the two satellites must be well inter-calibrated for TOA reflectances measurements and one spinoff from the current work is an additional satellite inter-calibration technique.

The most challenging task in the satellite AOD retrieval over land is separating the surface and aerosol contributions in TOA radiance. In order to have an AOD retrieval, the first

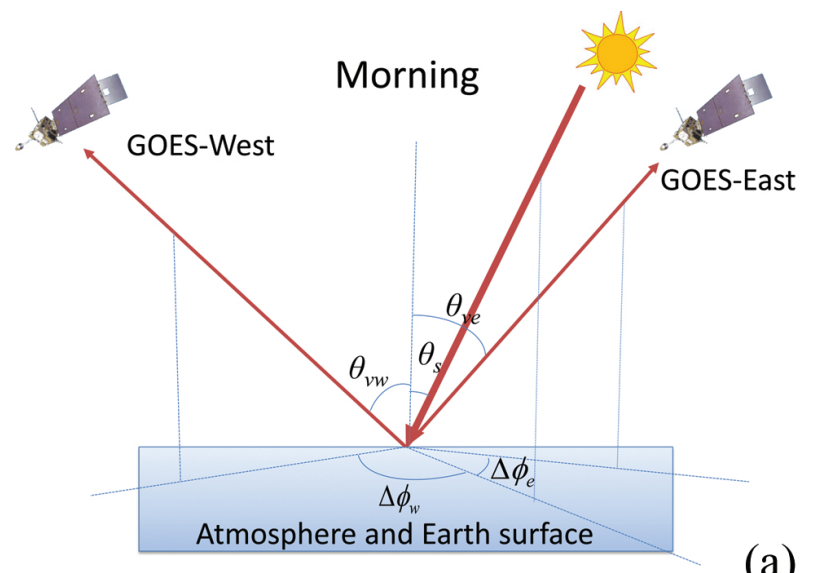

(a)

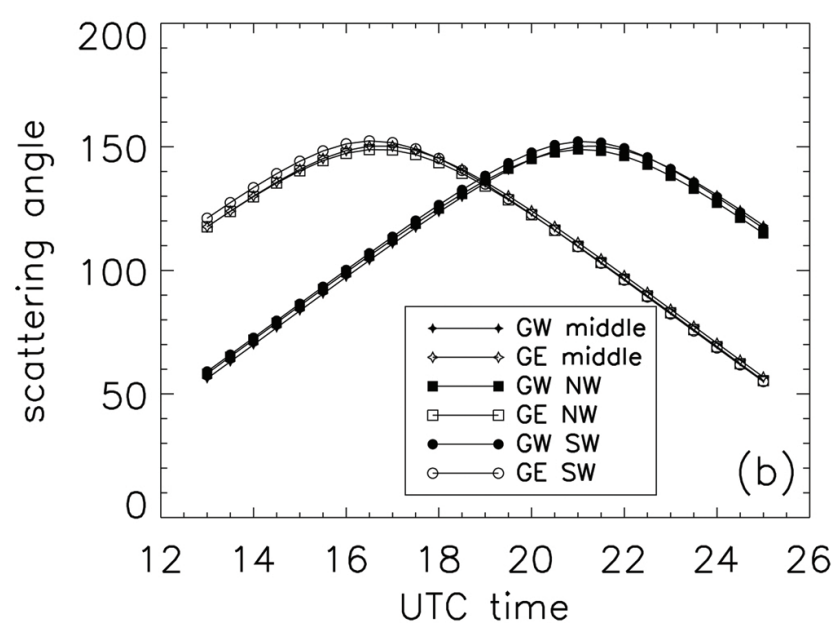

Fig. 1. (a) The scattering geometry of the Sun and the two GOES satellites in the morning for western US region. The angles in the figure are defined as following: $\theta_{\mathrm{S}}-$ solar zenith angle, $\theta_{\mathrm{vw}}-$ GOESWest view zenith angle, $\theta_{\mathrm{ve}}-$ GOES-East view zenith angle, $\Delta \phi_{\mathrm{W}}$ - relative azimuth angle between the Sun and GOES-West, $\Delta \phi_{\mathrm{e}}-$ relative azimuth angle between the Sun and GOES-East. (b) The scattering angle vs. UTC time of middle $\left(37.5^{\circ} \mathrm{N}, 105^{\circ} \mathrm{W}\right)$, northwest $\left(\mathrm{NW}, 50^{\circ} \mathrm{N}, 125^{\circ} \mathrm{W}\right)$, southwest $\left(\mathrm{SW} ; 25^{\circ} \mathrm{N}, 125^{\circ} \mathrm{W}\right)$ of the overlapping region for GOES-West (GW) and GOES-East (GE) on a selected day (19 June). The scattering angles do not vary much for the same satellite over different locations.

step is to retrieve the surface reflectance. Unlike MODIS, which uses multichannel information to retrieve surface reflectance and AOD, the current GOES imagers have only one visible channel for aerosol and surface reflectance retrieval, which limits their retrieval accuracy. In the operational GASP algorithm (Knapp et al., 2002, 2005; Prados et al., 2007), a clear-sky composite background image is generated for each observation time by selecting the second darkest pixel of the images over the past 28 days. Surface reflectance is retrieved from the composite clear-sky image assuming that the background AOD is 0.02 . The assumption in the GASP algorithm is that the surface reflectance is constant 
at each observation time during the 28-day period. This algorithm works well when the assumption holds, which usually occurs in summer. However, surface reflectance can change rapidly due to the change of the solar position, the change of surface vegetation, the change of the surface wetness and snow coverage during the 28-day period. For example, a change of surface reflectance from 0.11 to 0.14 in a 28-day period was observed at 16:45 UTC at GSFC (Goddard Space Flight Center) site in the fall (Zhang et al., 2011). Moreover, GASP can be affected by cloud shadows and underestimates the surface reflectance in the solar-satellite geometries where cloud shadows are often observed, e.g. in the afternoon over western US.

To address this problem, Zhang et al. (2011) developed a new AOD retrieval algorithm for the GOES imager by adapting the Multi-Angle Implementation of Atmospheric Correction (MAIAC) algorithm originally developed for MODIS (Lyapustin and Wang, 2008; Lyapustin et al., 2011a,b). While this paper will not reproduce the entire MAIAC logic, a brief description is necessary to understand the new hybrid algorithm. GOES MAIAC assumes that the surface BRDF (Bidirectional Reflectance Distribution Function) in channel 1 of GOES is proportional to a seasonally averaged BRDF in the $2.1 \mu \mathrm{m}$ MODIS channel. The coefficient of proportionality is derived through the time series analysis of the GOES visible channel images. This algorithm was shown to be more accurate than GASP over the western US where the surface reflectance is usually high, i.e. greater than 0.15 . However, this algorithm does not work well for backscattering view geometries (in the morning for GOES-East or in the afternoon for GOES-West as shown in Fig. 1b), where the surface reflectance is much larger (the hotspot effect). The MODIS angular sampling is usually different from that of GOES, and as a result, the use of the MODIS BRDF shape gives large errors when the GOES view angles are close to the backscattering direction where BRDF varies the most.

Over the western third of the US (to the west of $100^{\circ} \mathrm{W}$ ), observations are available from both GOES-East and GOESWest imagers for much of the day. Since GOES-East and GOES-West observe the same region in different geometries, the TOA reflectance from the two satellites has different sensitivity to AOD. This is illustrated in Fig. 2, showing computed TOA reflectance as a function of UTC time for different AOD values (0, 0.5, and 1.0) at Railroad Valley, Nevada, using BRDF typical for this location. One can see that GOES-West radiance has high sensitivity to AOD variations in the morning, before 17:00 UTC (the lines corresponding to different AODs in Fig. 2 are well separated), while the same is true for GOES-East in the afternoon, after 21:00 UTC, when both instruments sample the low part of surface BRDF in the forward scattering geometry. During the time between 17:00 and 21:00 UTC, neither is sensitive to AOD due to relatively high surface reflectance.

Another important reason for the high sensitivity of TOA reflectance to AOD in the forward direction is that the aerosol phase function is much larger in the low scattering angles. As shown in Fig. 3, the scattering phase function increases significantly for scattering angles below $100^{\circ}$, which coincides with the increase of the TOA reflectance sensitivity vs. AOD in the same scattering angles shown in Fig. 2.

Such a feature can be exploited if observations from both satellites are used simultaneously. This adds one more degree of freedom to enable better retrieval of the surface reflectance. In this work, a new "hybrid" algorithm is developed that uses data from both satellites. The algorithm first makes an estimate of average daily AOD from GOESMAIAC retrievals with best quality. Surface BRDF shape is updated using the time series of TOA reflectance and average daily AOD on the day with low daily AOD. The updated BRDF shape is used as a reference in the following day retrieval. AOD and surface reflectance are retrieved simultaneously using two satellite measurements at the same time.

Section 2 of this paper describes the data used in this work. Section 3 gives a description of the AOD versus TOA reflectance lookup procedure. Section 4 provides the detail of the algorithm. The algorithm validation based on AERONET data is described in Sect. 5, and Sect. 6 offers a new potential co-calibration philosophy for the two satellites.

\section{Data sources}

\subsection{GOES imagers}

Current GOES imagers have five channels, but only the visible channel can be used for aerosol retrieval. The current operational GOES-West is GOES-15, located above the equator at $135^{\circ} \mathrm{W}$, so the satellite can view only the western third of the United States. GOES-15 replaced GOES-11 and started its operation in December 2011. The current operational GOES-East is GOES-13. The previous GOES-East was GOES-12. GOES-12 stopped operation in April 2010 and was replaced by GOES-13. GOES-East is located at $75^{\circ} \mathrm{W}$ and it can view the whole continental US. For the "hybrid" algorithm to work, it is crucial that the two instruments are co-calibrated. The spectral response functions of the visible channel for the four satellite imagers are shown in Fig. 4 (data from ASPB and CIMSS Calibration Projects and Research, 2011). The differences of spectral response function (SRF) between GOES-11 and GOES-12 are small with the GOES-11 SRF slightly shifted towards red. Both GOES11 and GOES-12 visible channels cover the spectral range between $520 \mathrm{~nm}$ and $800 \mathrm{~nm}$. The GOES-13 and GOES-15 SRFs are different from the other two and they have narrower spectral range, from $520 \mathrm{~nm}$ to $720 \mathrm{~nm}$. Due to such difference, when switching from GOES-11 and GOES-12 pair to GOES-13 and GOES-15 pair in AOD retrieval algorithm, different look-up tables should be generated. In this study, GOES-11 and GOES-12 data are used. 

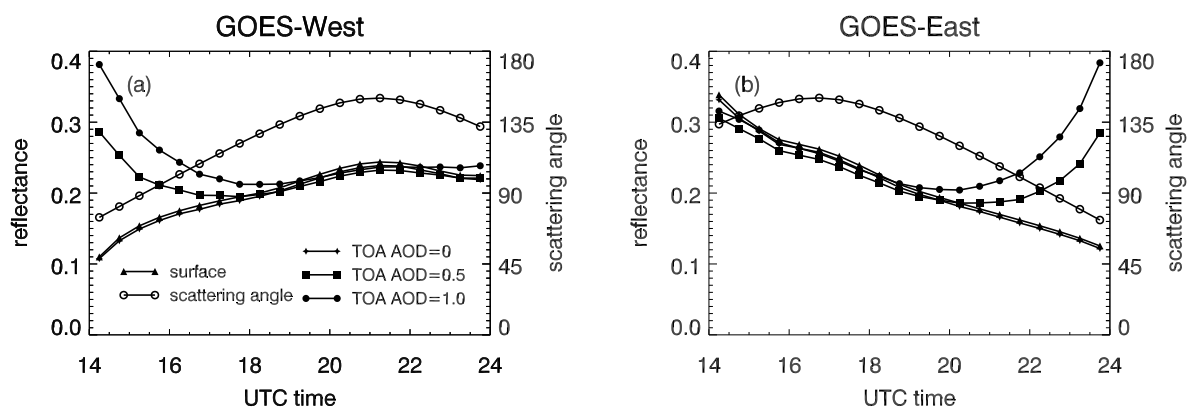

Fig. 2. TOA reflectance, surface reflectance and scattering angle vs UTC time calculated in the (a) GOES-West and (b) GOES-East geometry for Railroad Valley on a selected day (19 June 2008). The radiative transfer model, aerosol model and gases absorption parameters used are the same as those for the look-up table in Sect. 3.

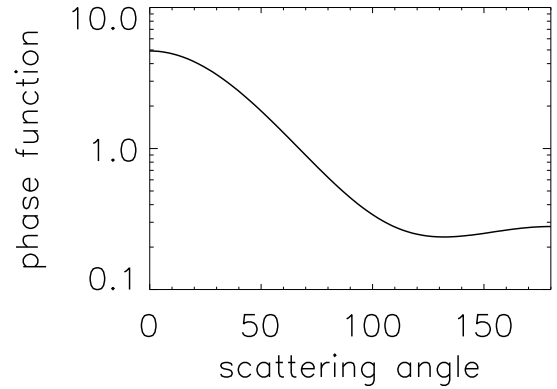

Fig. 3. Phase function of the aerosol model used in this work, which is derived from Mie calculation.

Calibration for the GOES visible channel uses two calculations: one to get the calibrated on orbit radiance from the photon counts on the detector and the second to obtain the TOA reflectance from the radiance (Weinreb et al., 1997). The radiance calibration between detectors on the same satellite imager has less than $1 \%$ difference. In addition, the sensor calibration changes exponentially over time due to the degradation of the sensor sensitivity. In this work, calibration coefficients are obtained from the NOAA GOES Calibration site (NOAA GOES Calibration, 2011). As will be demonstrated below, the new hybrid algorithm involves solving for both AOD and surface reflectances simultaneously from the two satellites' data. This offers a new opportunity to co-calibrate these satellites, which is discussed in Sect. 6, after the necessary explanation of the algorithm.

Prior to science processing, the image co-registration is applied to the GOES images to correct for jitter of the satellite orbit and correct the relatively low image navigation accuracy (4 km at nadir, GOES I-M databook, 1996). The procedure for co-registration of GOES-East image is the same as that described in Zhang et al. (2011). The incoming images are compared with a predefined reference image, which is built by regridding the average of $2.1 \mu \mathrm{m}$ band isotropic component of MODIS BRDF data on GOES grids, at locations with high contrast using correlation analysis. The high

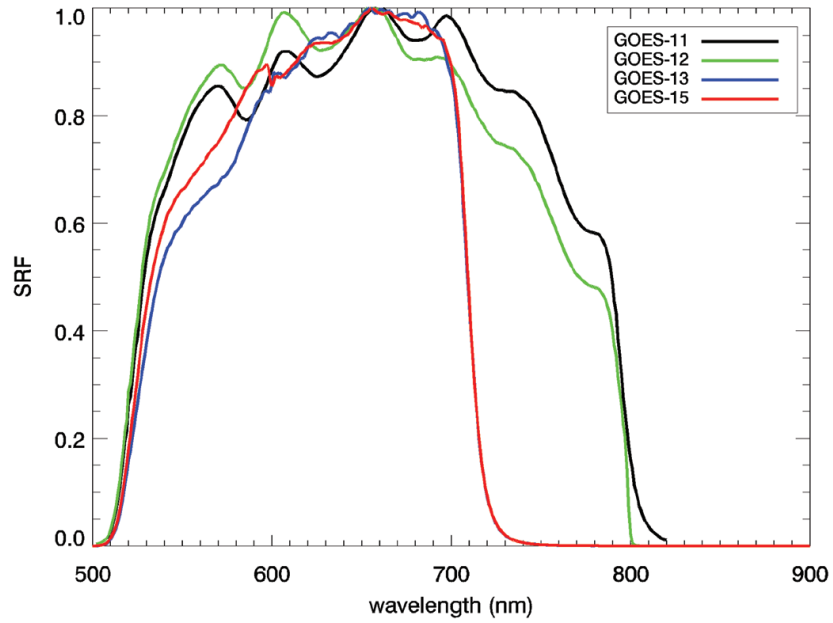

Fig. 4. Spectral response functions of the visible channels of the four GOES satellites (ASPB and CIMSS Calibration Projects and Research, 2011).

contrast reference points are mostly located along the coastlines. The shift at each high contrast location is determined first. Then, the shift of each pixel is determined through linear regression. For the GOES-West image, we first re-project it to the GOES-East grid, and then apply the above procedure.

After the image co-registration using the control points along the coast lines, the GOES-West pixels may still not be co-located with those of GOES-East because these control points are not distributed evenly across GOES-West images. The coastline control points are mostly located in the middle of the image from north to south. To further improve the image co-location between the two satellite images, GOES-East channel 1 image observed at the same time is used as the reference image and the same image co-registration algorithm is applied on the GOES-West image. The control points are selected such that they are evenly distributed over the whole image in cloud free conditions. 


\subsection{MODIS BRDF data}

Seasonally averaged MODIS BRDF (Schaaf et al., 2002) in the $2.1 \mu \mathrm{m}$ band is used as an aid for the retrieval of surface BRDF from GOES visible channel radiances in the MAIAC algorithm (Zhang et al., 2011).

The three Ross-Thick Li-Sparse (RTLS, Lucht et al., 2000) BRDF model parameters $\left(k_{\mathrm{iso}}, k_{\mathrm{geo}}, k_{\mathrm{vol}}\right)$ in the $2.1 \mu \mathrm{m}$ band are obtained from the MODIS land products MCD43D19, MCD43D20, and MCD43D21 with a spatial resolution of $1 \mathrm{~km}$. These BRDF parameters are derived from 16 days of MODIS surface reflectance (Vermote and Kotchenova, 2008) and are updated every eight days.

\subsection{AERONET data}

In the validation section below, the quality assured level 2.0 AERONET (AErosol RObotic NETwork, http://aeronet. gsfc.nasa.gov) AOD data is used for evaluating the AOD retrievals from GOES data. AERONET is a global ground aerosol monitoring network using CIMEL sun photometers. The AERONET AOD is treated as ground-truth since the AERONET AOD data have an accuracy of \pm 0.02 (Holben et al., 1998). Since AERONET AOD does not measure at wavelength $0.55 \mu \mathrm{m}$, it was calculated through log-linear interpolation between the two nearest wavelengths, i.e. $0.5 \mu \mathrm{m}$ and $0.675 \mu \mathrm{m}$. Three sites from western US are used in this study: UCSB $\left(\mathrm{CA} ; 34.415^{\circ} \mathrm{N}, 119.845^{\circ} \mathrm{W}\right)$, Railroad Valley $\left(\mathrm{NV} ; 38.504^{\circ} \mathrm{N}, 115.962^{\circ} \mathrm{W}\right)$ and Boulder $\left(\mathrm{CO} ; 40.045^{\circ} \mathrm{N}\right.$, $\left.105.006^{\circ} \mathrm{W}\right)$.

\section{Radiative transfer model and look-up table (LUT)}

The retrieval algorithm for AOD is implemented with the aid of a look-up table. The radiative transfer code SHARM (Spherical HARMonics) (Lyapustin and Wang, 2005) is used to calculate TOA reflectance for different geometries, surface reflectance, and AOD. To retrieve the surface reflectance, the RTLS BRDF model is used as it is in MAIAC (Lyapustin et al., 2011a,b; Zhang et al., 2011) and in the MODIS BRDF/albedo product (Schaaf et al., 2002). This model includes an isotropic term, a volume-scattering term, and a geometric term (Roujean et al., 1992), and the BRDF is written as

$$
\begin{aligned}
\rho_{\text {sfc }}\left(\theta_{\mathrm{s}}, \theta_{\mathrm{v}}, \Delta \phi\right)= & k_{\text {iso }}+k_{\mathrm{vol}} f_{\mathrm{vol}}\left(\theta_{s}, \theta_{\mathrm{v}}, \Delta \phi\right) \\
& +k_{\text {geo }} f_{\text {geo }}\left(\theta_{\mathrm{s}}, \theta_{\mathrm{v}}, \Delta \phi\right) .
\end{aligned}
$$

Here, $k_{\text {iso }}, k_{\mathrm{vol}}$, and $k_{\mathrm{geo}}$ are the model parameters, $f_{\mathrm{vol}}$ and $f_{\text {geo }}$ are pre-defined kernel functions depending only on the view geometry, defined by the triplet $\left(\theta_{\mathrm{s}}, \theta_{\mathrm{v}}, \Delta \phi\right)$ of the solar and view zenith angles and relative azimuth. Based on analysis of ground-based data as well as MODIS and POLDER measurements (Schaaf et al., 2002; Maignan et al., 2004), this model provides sufficient versatility and accuracy to describe bidirectional reflectance of natural surfaces.
Based on the Green's function RT solution with anisotropic surface (Lyapustin and Knyazikhin, 2001), the TOA reflectance can approximately be written as (Lyapustin and Wang, 2008; Lyapustin et al., 2011a)

$$
\begin{aligned}
\rho_{\mathrm{TOA}}\left(\theta_{\mathrm{s}}, \theta_{\mathrm{v}}, \Delta \phi\right)= & \rho_{D}\left(\theta_{\mathrm{s}}, \theta_{\mathrm{v}}, \Delta \phi\right)+k_{\text {iso }} F_{\text {iso }}\left(\theta_{\mathrm{s}}, \theta_{\mathrm{v}}\right) \\
& +k_{\mathrm{vol}} F_{\mathrm{vol}}\left(\theta_{\mathrm{s}}, \theta_{\mathrm{v}}, \Delta \phi\right) \\
& +k_{\mathrm{geo}} F_{\mathrm{geo}}\left(\theta_{\mathrm{s}}, \theta_{\mathrm{v}}, \Delta \phi\right)
\end{aligned}
$$

where $\rho_{D}$ represents the atmospheric path reflectance, $k_{\text {iso }}$, $k_{\mathrm{vol}}, k_{\mathrm{geo}}$ are RTLS coefficients defined in Eq. (1), $F_{\text {iso }}$, $F_{\text {vol}}, F_{\text {geo }}$ are the integrals from the atmospheric upward and downward bidirectional transmittance multiplied by the isotropic, geometric and volumetric BRDF kernels $f_{\text {iso }}, f_{\text {geo }}, f_{\text {vol }}$, respectively. For the GOES visible channel, these functions depend on the aerosol properties (e.g. AOD) and geometry. The detailed expressions can be found in Lyapustin and Wang (2008). Equation (2) also ignores a nonlinear term describing multiple scattering of photons between the surface and atmosphere, which is small for most surfaces.

An accurate accounting for anisotropic surface reflectance is important when the surface anisotropy and the diffuse surface irradiance are high, e.g. at shorter wavelengths, higher scattering optical depth and larger air mass (high zenith angles) (e.g. Wang et al., 2010). At the longer wavelength of the GOES visible channel compared to the $0.466 \mu \mathrm{m}$ channel used in MODIS and the MODIS MAIAC algorithm, both Rayleigh and aerosol optical depth are lower in the GOES configuration. In this case, use of Lambertian assumption, which offers a much simpler mathematical model, gives an adequate accuracy as compared to other error sources. For example, Zhang et al. (2011) evaluated the GOES AOD retrieval uncertainty from the Lambertian assumption as less than $20 \%$. Therefore, in this study, the surface reflectance in the viewing geometry is used and assumed to be the lambertian value for the AOD LUT.

The LUT was generated using an aerosol model with fine and coarse fractions with lognormal size distribution and the following (volumetric) parameters: radius $R_{\mathrm{V}}=0.14 \mu \mathrm{m}$ and $3.2 \mu \mathrm{m}$; standard deviation $\sigma_{\mathrm{v}}=0.35 \mu \mathrm{m}$ and $0.7 \mu \mathrm{m}$; real and imaginary part of index of refraction $n_{\mathrm{r}}=1.45$ and $n_{\mathrm{i}}=0.006$. The ratio of volumetric concentrations between the coarse and the fine mode is $C_{\mathrm{v}, \text { coarse }} / C_{\mathrm{v}, \text { fine }}=0.5$. Fixed climatological values of column ozone and water vapor for gaseous absorption calculation are applied in the calculation of the LUT following Knapp et al. (2002) and Zhang et al. (2008).

The LUT stores $\rho_{D}$ and functions for calculating $F_{\text {iso }}$, $F_{\text {vol }}, F_{\text {geo }}$ at different geometry and AOD, similar to that used in Lyapustin et al. (2011a) but for single aerosol model and single band. The LUT is used in retrieving surface reflectance, AOD and calculating sensitivity quantities in the retrieval algorithm as described in the following section. 


\section{Hybrid algorithm description}

In the previous sections, the groundwork for understanding the hybrid algorithm is given. Several steps are taken in the algorithm for each pixel: (1) daily average AOD is estimated for each pixel using the GOES-MAIAC AOD retrieval algorithm with best quality. Low daily AOD days are selected for BRDF update. (2) A time series of surface reflectance is retrieved using the daily average AOD and TOA reflectance for one to three consecutive low AOD days. (3) The surface reflectance time series is then used to retrieve surface BRDF, i.e the three RTLS coefficients. In low AOD days, surface reflectance can be retrieved more accurately, since they tend to have high signal to noise ratio and less interference of AOD model choice. Furthermore, low AOD days also have less AOD temporal variability and average daily AOD can be used without much potential error. (4) The surface BRDF shape is used as a reference for the following day surface reflectance and AOD retrieval at each observation time. In this step, surface reflectance is assumed to be different from the previous day but has the same BRDF shape. Because of two TOA reflectance measurements from the satellites, both surface reflectance and AOD can be retrieved at the same time. This can potentially improve AOD retrieval accuracy in periods when surface reflectance changes rapidly from one day to another.

Figure $5 \mathrm{a}$ and $\mathrm{b}$ show the flow chart of the hybrid algorithm that uses both GOES-East and GOES-West data. Steps in the figure are identified by the corresponding section numbers in the text below.

First, the cloud mask algorithm CLAVR (Clouds from Advanced Very High Resolution Radiometer; Stowe et al., 1999; Heidinger et al., 2001) is applied to detect cloudy pixels. CLAVR has been used in GOES-MAIAC (Zhang et al., 2011) and GASP (Prados et al., 2007) algorithms. It uses two IR channels, 2 and 4, along with the visible channel. While the visible channel 1 has spatial resolution of $1 \mathrm{~km}$, it is the resolution of IR channels $(4 \mathrm{~km})$ that define spatial resolution of both cloud mask and AOD retrievals.

The GOES-MAIAC algorithm, which uses seasonallyaveraged MODIS BRDF at $2.1 \mu \mathrm{m}$, works well over the western US for the low scattering angles, namely for the range of scattering angles $<100^{\circ}$ (Zhang et al., 2011). In the new hybrid algorithm, the task is to obtain the correct BRDF for the full range of view angles. The new version of the algorithm expands GOES processing to cover the full range of GOES observations as follows.

\subsection{AOD pre-screening for BRDF update}

Armed with the knowledge of the BRDF from prior days, the first step is to determine whether the BRDF shape has changed due to meteorological (rain, snow, etc.) and vegetation factors. This assessment can only be done on days with low AOD load for the GOES pixels. The morning data from GOES-West and the afternoon data from GOES-East, obtained in the forward scattering directions where the sensitivity of measurements to AOD is high, are used to derive an AOD estimate using the GOES-MAIAC algorithm. Since the horizontal scale of aerosol variability is approximately $80 \mathrm{~km}$ (Anderson et al., 2003), a $100 \times 100 \mathrm{~km}^{2}$ region is used to estimate the average AOD from MAIAC as a screening tool for low AOD days over a pixel. This step requires a low sensitivity of retrieved AOD to the surface reflectance error (largely a scattering geometry constraint). A constraint that at least $40 \%$ of the pixels in this region have AOD retrievals is also used to eliminate cloudy regions.

In the previous analysis of GOES-East data, Zhang et al. (2011) found that the GOES-MAIAC algorithm has a good AOD retrieval accuracy over the western US in the afternoon, for the forward scattering geometries when surface BRDF is low and sensitivity of TOA reflectance to AOD is high. The GOES-West instrument samples similar view geometries (forward scattering) in the morning for the western US. Therefore, the average $\mathrm{AOD}^{\mathrm{av}}$ is obtained as an average from GOES-East AOD and GOES-West AOD retrieved from GOES-MAIAC at the observations with scattering angle less than $100^{\circ}$. The day is marked as low AOD day (good for BRDF retrieval) if both AODs are below 0.3 and agree with each other to within 0.1 so that the AOD variation is estimated to be below 0.05 .

\subsection{Retrieve surface reflectance}

Low AOD days are defined when both morning and afternoon AOD are similar and low $(\mathrm{AOD}<0.3)$. On such days, typical diurnal variation of AOD is also small (e.g. Smirnov et al., 2002), and the effect of AOD on retrieved surface reflectance is small and assumed constant. This average $\mathrm{AOD}^{\mathrm{av}}$ is used to derive the BRDF shape from both GOES-West and GOES-East data for the full range of GOES observation geometries including the backscattering direction.

The time series of one to three days of GOES channel 1 images are required to derive surface BRDF of the entire image. Since the GOES imager makes an observation every half hour, there are about a hundred images during the three daytime intervals from both GOES imagers.

A set of filters is applied to the accumulated time series to reduce possible noise:

1. Cosine of solar zenith angle should be larger than 0.3 $\left(72^{\circ}\right)$. Because the surface reflectance retrieved at high solar zenith angle is less accurate due to the increased sensitivity of TOA reflectance to the AOD variations, the observations with high solar zenith angle are removed in the BRDF retrieval.

2. To further reduce interference from cloud, cloud shadow and large variations of AOD, a filter is applied to remove measurements with large variations in the accumulated time series. This filter assumes that surface 


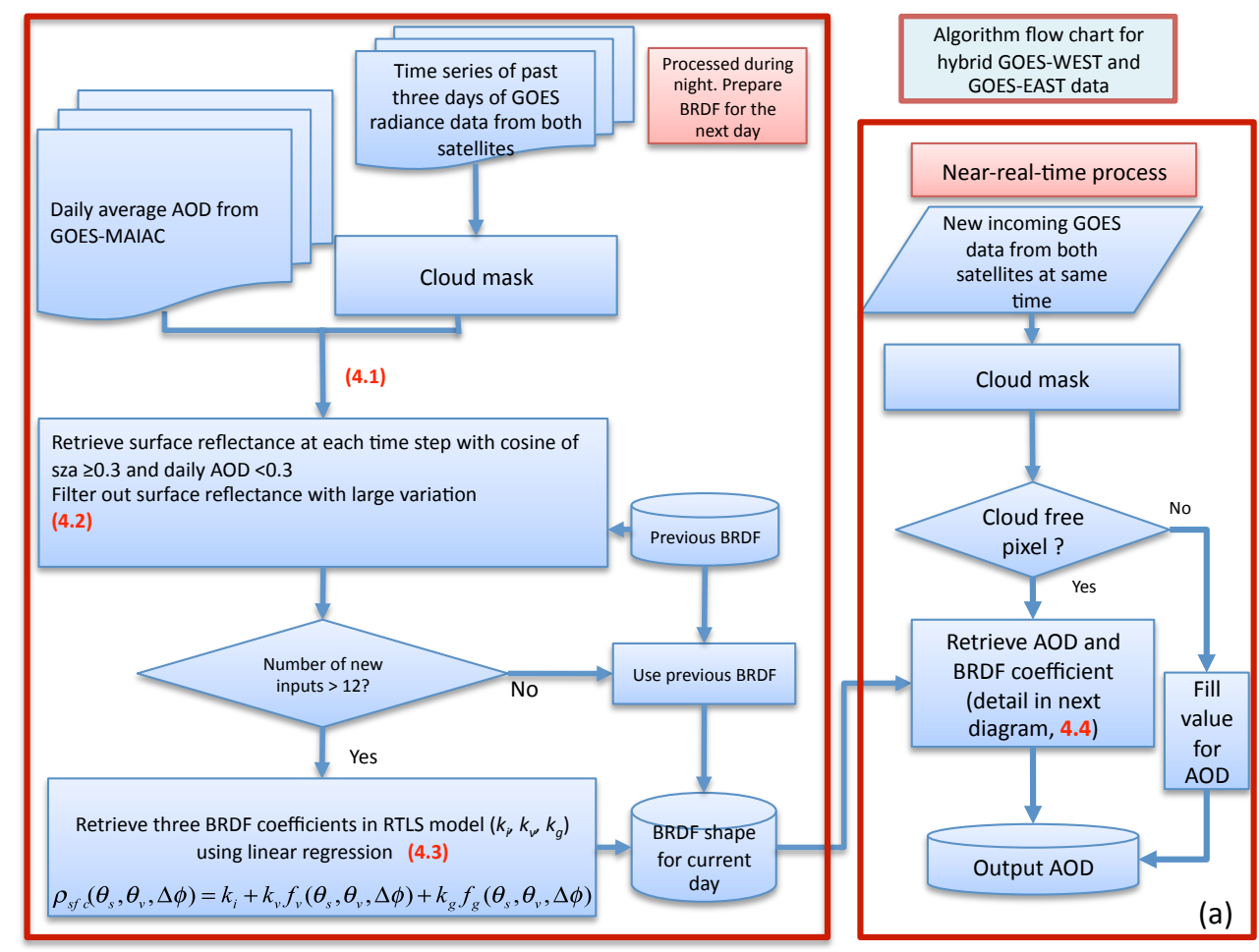

Fig. 5. (a) Flow chart. Section number descriptions in the text are noted to help follow the flow of the hybrid AOD and BRDF retrieval algorithm. (b) Detailed steps for AOD and BRDF coefficient retrieval in (a).

BRDF is stable for the period of one to three days, and thus, the previous surface BRDF can be used as reference $\left(\mathrm{BRDF}^{\mathrm{Ref}}\right)$ to filter measurements producing large deviations from the reference value. The threshold for this test is set to the bigger of $0.4 \mathrm{BRDF}^{\mathrm{Ref}}$ and 0.04 . The value of the threshold is chosen through observations of surface reflectance variation from day to day. For a given observation time, the surface reflectance variation is usually observed to be about $10 \%$ or $20 \%$ and mostly below 0.03 or $30 \%$. Therefore, variation larger than the threshold is most likely to be introduced by cloud, cloud shadow or large AOD variation and such data should be removed.

On the other hand, to account for a seasonal or rapid surface change, this filter is not applied if more than $85 \%$ of the new surface reflectance values are systematically higher or lower than the reference values.

3. In addition, the surface reflectance sequence is sorted by UTC time. It is assumed that the surface reflectance does not change much from one time step to another observed from a specific satellite. The surface reflectance at a particular time should be within a range determined by the values in the sequence before and after it, and it is removed if it falls outside that range. In the current implementation, the threshold for this filter is set to 0.03 or $30 \%$ of the surface reflectance, whichever is larger.
Similar to the previous one, the threshold is also chosen through the observation of the data: as shown in Fig. 2 and later in Fig. 9, the variation of surface reflectance in a half hour is usually less than 0.02 or $20 \%$.

\subsection{BRDF update}

After application of the filters, the BRDF is updated by fitting the sequence of the surface reflectances to the RTLS model described in Eq. (1) if the number of remaining measurements is larger than 12. If the number of new measurements is less than 12, the preexisting BRDF is assumed valid.

In the real-time processing, the BRDF retrieval process is performed during the night when all the daytime GOES data are available. The updated BRDF is used on the following day together with the new incoming GOES data for the surface reflectance and AOD retrieval.

\subsection{AOD retrieval on current day data}

As mentioned before, the surface reflectance is found to be changing from day to day with a magnitude about $10 \%$ to $20 \%$. Therefore, the current surface BRDF is not assumed to be the same as the one retrieved in the last step, but is assumed proportional to the one updated in the previous step instead: 


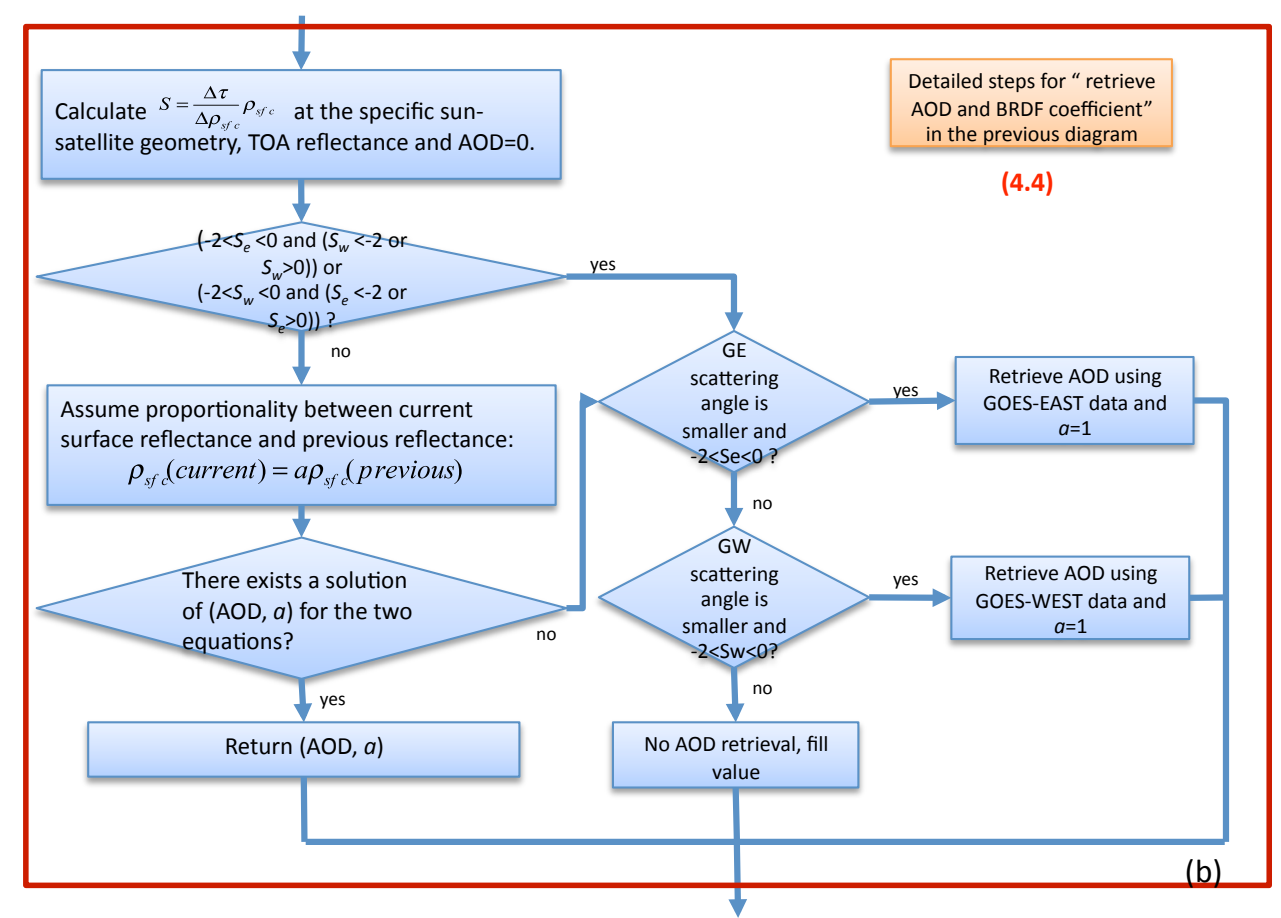

Fig. 5. Continued.

$\rho_{\mathrm{sfc}}\left(\theta_{\mathrm{s}}, \theta_{\mathrm{v} i}, \Delta \phi_{i}\right.$, current $)=a \rho_{\mathrm{sfc}}\left(\theta_{\mathrm{s}}, \theta_{\mathrm{v} i}, \Delta \phi_{i}\right.$, previous $)$,

where $i=e, w$ represents two satellite geometries for GOES-East and GOES-West, respectively, and $a$ represents a BRDF scaling factor. At any given time, there are two equations for the two GOES (-West and -East) measurements from Eq. (2):

$$
\begin{aligned}
\rho_{\mathrm{TOA}, i}(\tau, a)= & \rho_{D, i}(\tau)+a\left(k_{\mathrm{iso}} F_{\mathrm{iso}, i}(\tau)+k_{\mathrm{geo}} F_{\mathrm{geo}, i}\right. \\
& \left.+k_{\mathrm{vol}} F_{\mathrm{vol}, i}(\tau)\right),
\end{aligned}
$$

where the geometry variables are fixed for a given observation time and are represented in the index $i$ for the two satellites.

The equations can be solved for two unknowns, $a$ and AOD $(\tau)$. In many cases, this approach provides a reasonable solution while in other cases the retrieved values $(a, \tau)$ may have large uncertainty.

Figure 6 shows solution curves of $(a, \tau)$ for simulated TOA reflectances from the two satellites at Boulder at two observation times. The $(a, \tau)$ pairs on the GOESEast/GOES-West curves satisfy the measurement for the respective view geometry, and the solution $(a, \tau)$ is represented by the intersection points of the curves. Although both cases have solutions, the case shown in Fig. $6 \mathrm{~b}$ is strongly sensitive to the measurement uncertainties caused by the factors such as calibration, cloud contamination, etc. Thus, when slopes of the two curves are found close (as in Fig. 6b), $a$ is assumed
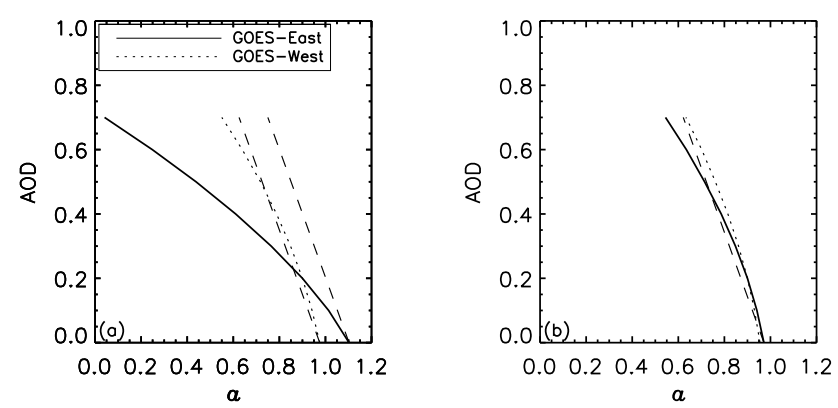

Fig. 6. AOD and surface reflectance solution curves for two satellite geometries at Boulder (a) 22:00 UTC and (b) 20:00 UTC, where $a$ represents surface reflectance normalized by the previous day surface reflectance. The TOA reflectance was calculated using $a=0.9$ and $\mathrm{AOD}=0.2$. The long dashed lines have slopes of -2 . If a solution curve is to the right of the long dashed line, i.e. the absolute value of the slope of the curve is greater than that of the long dashed line, the TOA reflectance is not sensitive to the AOD variations, and vice versa.

to be 1 and AOD is retrieved using the sensor (-East or -West) that is more sensitive to AOD variations.

The $(a, \tau)$ retrieval process for this step is shown in Fig. $5 b$. The quantity $S=\frac{\Delta \tau}{\Delta \rho_{\mathrm{sfc}}} \rho_{\mathrm{sfc}}$, computed at AOD $=0$ for the corresponding geometry and TOA reflectance, is used to differentiate the two situations in Fig. 6, since it is the slopes of the curves. At a given observation time, $S$ for GOES-East and GOES-West, i.e. $S_{\mathrm{e}}$ and $S_{\mathrm{w}}$ are calculated from LUT. 
The AOD retrieval has small sensitivity to surface reflectance error if $S$ is less than 0 and has a small absolute value. Otherwise AOD retrieval is sensitive to surface reflectance error. If one of $S$ is between 0 and -2 and the other $S$ is less than -2 or greater than 0 , the slopes between the two curves are separate (as in Fig. 6a) and thus we can retrieve the BRDF coefficient and AOD at the same time. Otherwise, $a$ is assumed to be 1 and AOD is retrieved using the satellite data with smaller scattering angle, which is more sensitive to AOD, if it is sensitive enough to AOD, i.e. $-2<S<0$. The choice of a threshold of -2 is empirical and through the tests of different values.

\section{Results}

\subsection{Comparison to AERONET AOD}

The AOD retrieval results are compared against the AERONET measurements at three AERONET sites located in the western United States: Railroad Valley, UCSB, and Boulder. GOES AOD retrievals within a $5 \times 5$ box $(20 \times$ $20 \mathrm{~km}^{2}$ ) surrounding the AERONET site are averaged and the two closest AERONET measurements within $15 \mathrm{~min}$ before and after the GOES observation are interpolated to the GOES observation time. In cases where only one AERONET measurement is available within a $15 \mathrm{~min}$ time frame, that value is used instead of interpolation. To further remove cloud contamination, it is required that at least 10 retrievals among the 25 pixels and the standard deviation of AOD in the $5 \times 5$ box are less than 0.2 . The hybrid algorithm only works when both satellites have observations at the same time. At some observation times, there are no data from both satellites, i.e. GOES-West does not have observations at 15:15, $15: 45,18: 15,21: 15$, and 21:45 UTC. As mentioned before, the data for GOES-East is from GOES-12 and the data for GOES-West is from GOES-11. The time period of the data is from 1 March 2008 to 31 October 2008.

The hybrid algorithm introduced above can also be run using single satellite data if the proportionality coefficient $a=1$ is assumed. The single satellite algorithm was run on the three sites as well as the new hybrid algorithm and their results are compared. In Fig. 7, the results of validation of the hybrid algorithm are shown for western sites: UCSB, Railroad Valley and Boulder. In all three sites, the number of retrievals have increased in the hybrid algorithm over the individual satellite retrievals, by $5 \%$ to $80 \%$ for the three sites. At Boulder, the hybrid algorithm also improves the retrieval accuracy., The RMSE reduces to 0.06 for the hybrid algorithm compared to 0.09 for GOES-West and 0.10 for GOES-East. At the other two sites, the accuracy of the hybrid algorithm is similar to the single satellite algorithm. At UCSB, the surface reflectance is low in all the geometries, i.e. below 0.1 most of the time, the retrieval can be obtained from both satellite retrievals. Therefore, the number of the hybrid retrieval is similar to those of the single satellite retrievals. At the other two sites, the surface reflectances are higher and there are observation times when single satellite measurement is not sensitive enough to have good retrievals. Thus, the number of hybrid retrievals is much larger than the number of single satellite retrievals at these two sites.

This example demonstrates the complementary nature between GOES-West and GOES-East. For any single sensor over a surface with high surface reflectance, there is an observation time period when AOD cannot be retrieved due to low sensitivity to aerosol variations (large scattering angles). The hybrid algorithm solves this problem because the other sensor has a view geometry, favourable for aerosol retrieval, for the same period.

A combined method can also be applied to merge the retrievals from the single satellite retrievals: the AOD retrievals are selected from the satellite that has smaller scatter angle. Smaller scatter angle implies smaller surface reflectance and better sensitivity to AOD variations. The results of the combined algorithm at the three sites are shown in the last column of Fig. 7. The number of retrievals of the combined algorithm is similar to that of the hybrid algorithm. The accuracy of the combined algorithm is also similar to the hybrid algorithm at UCSB and Railroad Valley. But it is less accurate than the hybrid algorithm at Boulder, although it has improved accuracy over single satellite retrieval.

MODIS AOD retrieval over land has an expected error (EE) of $\pm(0.05+0.15 \tau)$ and more than $68 \%$ (one standard deviation) AOD retrievals are within EE (Levy et al., 2010). The lines of the EE are plotted in Fig. 7 to evaluate the AOD retrieval against this criterion. The results show that at the three sites more than $74 \%$ of retrievals are within EE. Therefore, the hybrid GOES AOD retrievals have similar accuracy as MODIS AOD using this criterion.

The scatter plots also show that the retrieved AOD is biased higher than AERONET AOD. This is due to the uncertainties in the algorithm, which will be discussed in Sect. 5.2. The most possible reason for this bias is cloud contamination, which tends to increase the magnitude of the retrieved AOD. GOES has limited spectral resolution and therefore cloud screening capability is not as good as that of MODIS.

Figure 8 shows the diurnal variation of RMSE in AOD retrievals from the hybrid algorithm, the combined algorithm and single satellite algorithms, along with the average AOD from AERONET. The RMSEs are calculated for the coincident data that are contained in the retrievals from both hybrid and combined algorithms. At Boulder, the hybrid algorithm has lower RMSE most of the time. At the other two sites, there are no significant differences between the two algorithms.

To understand the reason that the hybrid algorithm is more accurate than the other algorithms at Boulder but not at the other two sites, Fig. 9 shows the diurnal variation of the surface reflectance from BRDF retrieval over the three sites. Of the three sites, UCSB has the lowest surface reflectance 

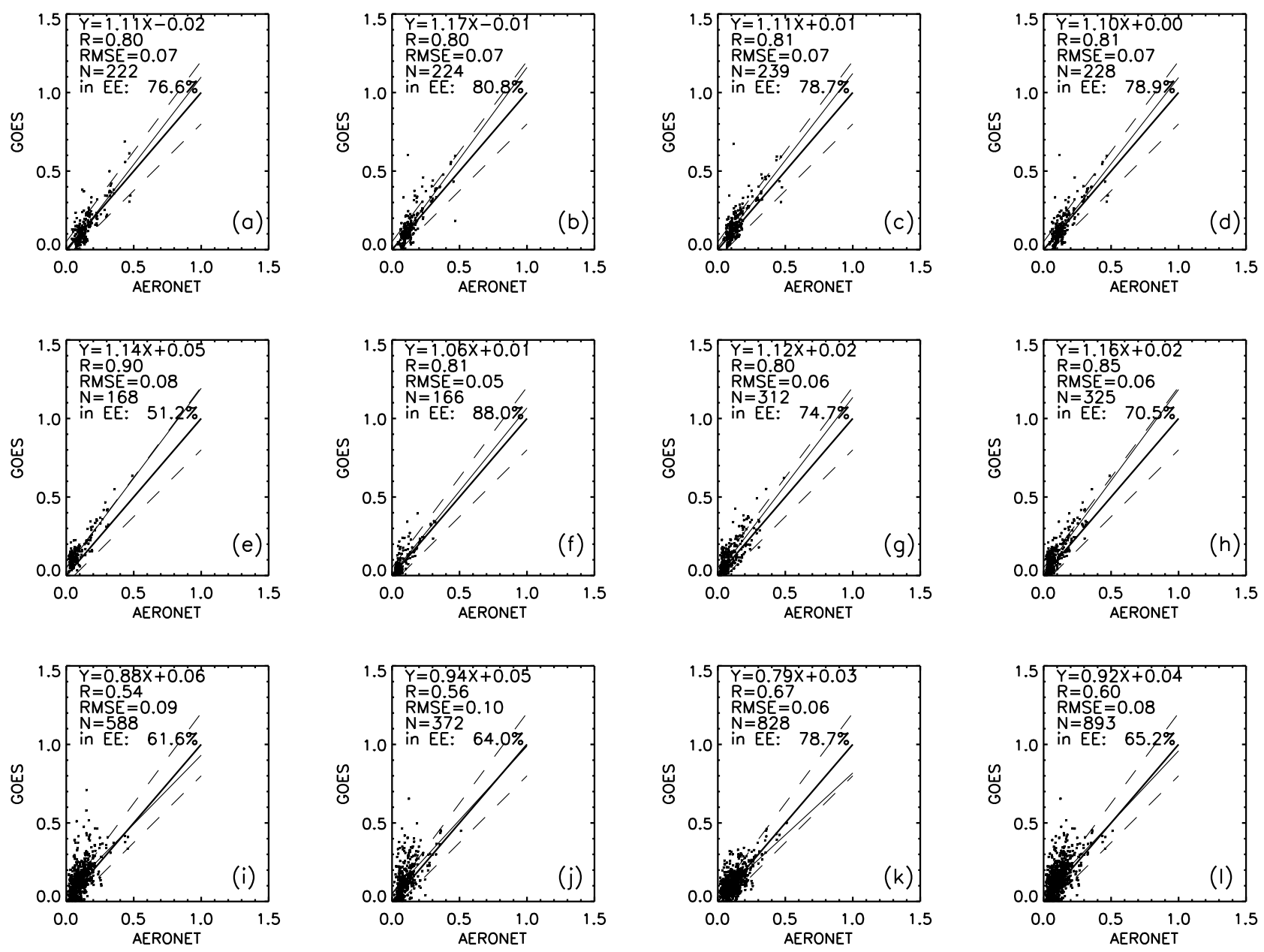

Fig. 7. Scatter plots of AOD for GOES-WEST vs. AERONET (column 1), GOES-EAST vs. AERONET (column 2), hybrid algorithm vs. AERONET (column 3), and combined algorithm vs. AERONET (column 4) at three AERONET sites: UCSB (top row), Railroad Valley (middle row), and Boulder (bottom row). The regression lines are calculated through least-square fit. $1: 1$ lines (solid) and $\tau_{\text {AERONET }} \pm\left(0.05+0.15 \tau_{\text {AERONET }}\right)$ lines (dashed) are also plotted in the figure. Statistics written in the plots include linear regression equations, correlation coefficients $(R)$, root mean square error (RMSE), total number $(N)$, and percentage within expected error (EE, $\pm(0.05+0.15 \tau))$.

and Railroad Valley has the highest. The hybrid algorithm can improve retrieval if TOA reflectance from one satellite is more sensitive to aerosol and that from the other is more sensitive to the surface. The difference between the hybrid algorithm and the other algorithms comes mainly from the difference in $a$ value and its effect on AOD retrievals. For UCSB, the surface reflectance is about 0.04 from the satellite with lower scattering angle. The surface variation from one day to another is usually below $20 \%$. A $20 \%$ correction from $a$ value can introduce 0.008 change in surface reflectance and corresponding AOD correction is of magnitude of $0.05-0.1$, which is probably too small to show the effect in the statistics. For Railroad Valley, the surface reflectance between 17:00 to 22:00 UTC is around 0.2 and is so high that the TOA reflectance is not sensitive to AOD enough to have AOD retrievals. For observation times before 16:00 UTC, the low scattering angle makes the AOD retrieval less sensitive to the correction of surface reflectance. Therefore, the effect of $a$ correction is also small at Railroad Valley. At Boulder, the low surface reflectance is about $0.1-0.15$. A correction of $20 \%$ can introduce a $0.02-0.03$ change in surface reflectance retrieval, which is about a $0.1-0.3$ change in AOD, which is much larger than those of UCSB. This is probably the reason that the improvement of using the hybrid algorithm is only observed at Boulder but not at the other two sites.

\subsection{Uncertainty of the algorithm}

Many factors introduce uncertainties in the AOD retrievals of this algorithm, which include the use of average daily AOD on surface BRDF retrieval, choice of aerosol model, calibration errors, cloud contaminations, etc. 

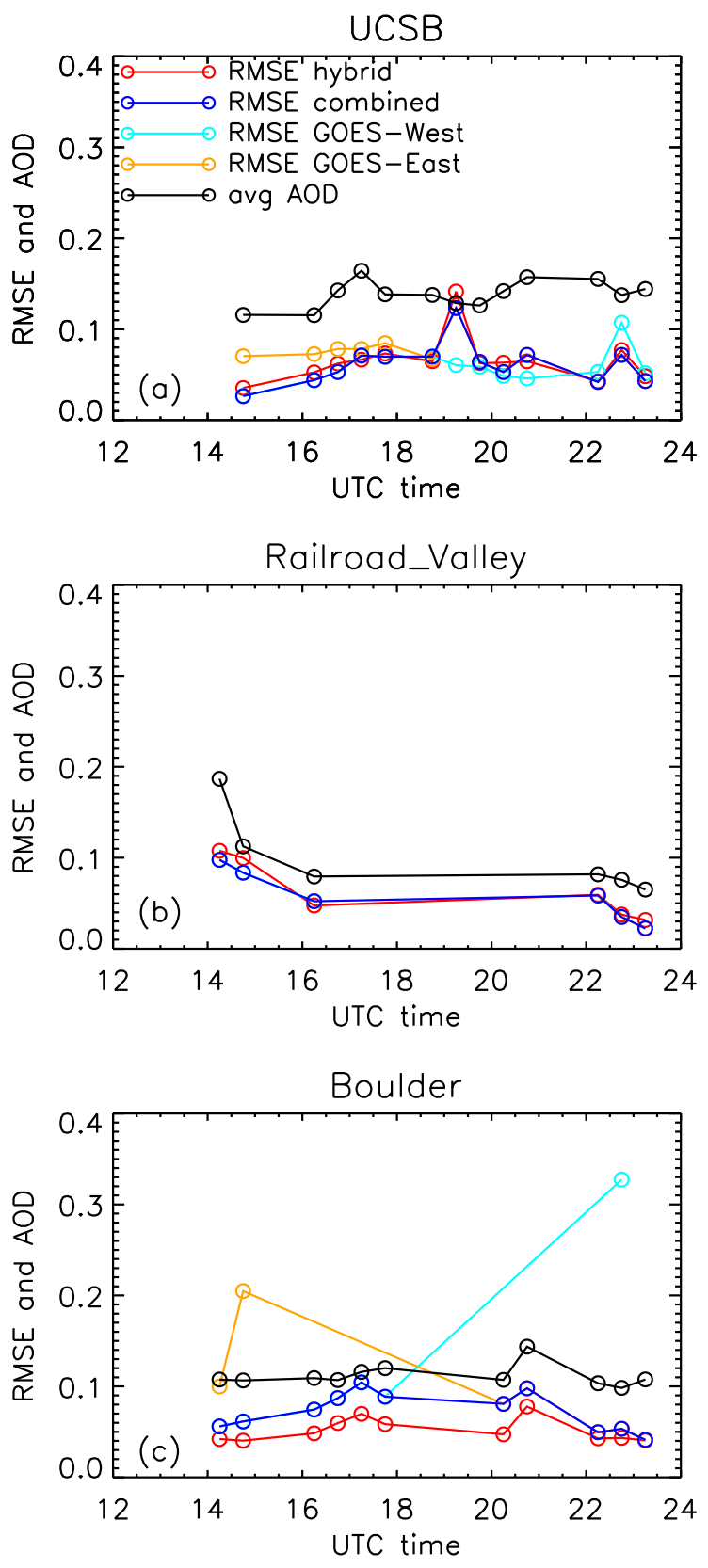

Fig. 8. Diurnal variation of RMSE in GOES AOD retrievals for the four algorithms along with the average AERONET AOD.

Analysis of the diurnal cycle of AOD based on AERONET data was done previously (e.g. Smirnov et al., 2002). Among other results, this work showed low daily variability of AOD in clear conditions with low aerosol concentration. Here, an additional analysis is conducted based on time series of AERONET measurements at the three western US sites used in this work. Figure 10 shows the histogram of daily standard deviation of AOD for the days with average AOD less than 0.3 , using data from 2001 to 2008 . One can see that the standard deviation of AOD is generally below 0.05 , indicating

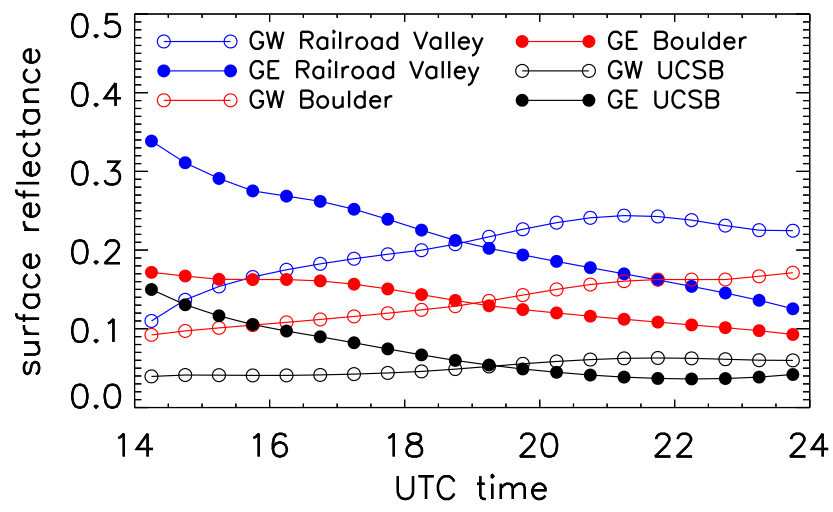

Fig. 9. Diurnal variation of surface reflectance at the three AERONET sites on 19 June 2008, where GW represents GOESWest and GE represents GOES-East.

that a daily average $\mathrm{AOD}\left(\mathrm{AOD}^{\mathrm{av}}\right)$ can be used to retrieve BRDF for low AOD days with sufficient accuracy.

The errors in $\mathrm{AOD}^{\mathrm{av}}$ will propagate into BRDF retrievals and will affect the subsequent AOD retrievals. Assuming that $\mathrm{AOD}^{\mathrm{av}}$ was overestimated by $\Delta \tau$, one can expect that this will lead to an overestimation of AOD on the subsequent days (through BRDF-error) close to $\Delta \tau$. Figure 11 shows the result of such sensitivity study conducted for the surface reflectance 0.1 and overestimation $\Delta \tau=0.05$ of $\mathrm{AOD}^{\mathrm{av}}$ for different daily AOD values. The error of 0.05 in AOD is chosen because the standard deviation of AOD on low AOD days are mostly smaller than 0.05 , as shown above. The overestimation of AOD on the subsequent days is found to be close to 0.05 . The error is slightly larger at low AOD and becomes lower than 0.05 at larger AOD. The same analysis for a 0.05 underestimation of $\mathrm{AOD}^{\mathrm{av}}$ and for different surface reflectances shows a similar magnitude for AOD errors. Based on this consideration, the criterion $\mathrm{AOD}^{\mathrm{av}}<0.3$ is found to be acceptable within that error in order to select low AOD days for the BRDF retrieval.

Single visible channel retrieval for GOES restricts the freedom in choosing the aerosol models. Therefore, a single aerosol model has to be assigned in the algorithm. As analyzed in Zhang et al. (2011), an error of $25 \%$ in AOD retrieval can result from uncertainty in the aerosol model. The AOD error in this algorithm should be of similar magnitude.

As will be shown in Sect. 6, the GOES sensors have a calibration error about $5 \%$, which can introduce uncertainty in AOD retrieval. However, since the surface reflectance is also retrieved from the same GOES measurements, the AOD error can be partially compensated. For example, an overestimate of TOA reflectance can also introduce an overestimate in surface reflectance and therefore the overestimate of AOD can be reduced. An overestimate (underestimate) of TOA reflectance of $5 \%$ can introduce an overestimate (underestimate) of surface reflectance of $8 \%$, which will be shown in Sect. 6. Simulations were performed by perturbing 


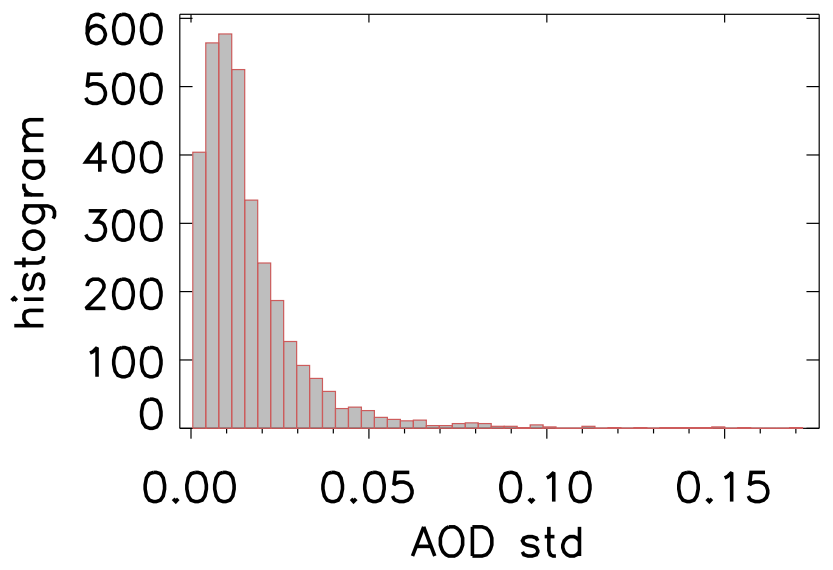

Fig. 10. Histogram of daily standard deviation of AOD with average values less than 0.3 at the three AERONET sites, from 2001 to 2008.

TOA reflectance by $5 \%$ and surface reflectance by $8 \%$ correspondingly for different geometries, surface reflectance, and AOD. AOD was retrieved using the perturbed inputs and compared with the original AOD. The results show that the uncertainty from calibration is about $3 \%$ for low AOD $(<0.3)$, and about $10 \%$ for high AOD $(\sim 1.0)$.

\subsection{A regional AOD retrieval example}

Figure 12 shows the AOD retrieval maps for a California fire case on 10 July 2008 at 16:45 UTC and at 22:15 UTC, including AOD retrievals from single satellite algorithm for GOES-West and GOES-East and those from the hybrid algorithm. The AOD retrievals from the combined algorithm are the same as the single satellite algorithm with smaller scattering angles, i.e. GOES-West at 16:45 UTC and GOES-East at 22:15 UTC, and therefore not plotted. At 16:45 UTC (local morning), channel 1 observation from GOES-East corresponds to a large scattering angle and high surface reflectance when accurate aerosol retrieval is not possible. At the same time, the GOES-West observation for the same scene has more favourable geometry with low surface reflectance, and as a result, GOES-West gives much better AOD retrieval coverage as compared to GOES-East at 16:45 UTC. The hybrid algorithm at 16:45 UTC gives retrieval coverage similar to that of GOES-West since it primarily relies on GOES-West data, which has good sensitivity to AOD. The situation is reversed at 22:15 UTC (local afternoon), when GOES-East becomes the primary sensor for AOD retrievals and gives the better retrieval coverage. Thus, the hybrid algorithm maximizes the retrieval coverage/accuracy from individual sensors and provides the best diurnal coverage and accuracy.

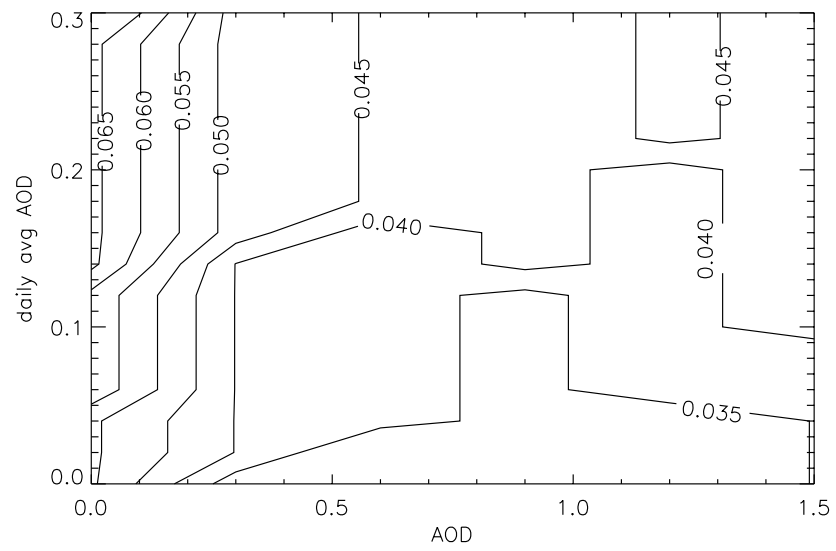

Fig. 11. Sensitivity of AOD retrieval to the errors in daily average AOD. The geometry is set for GOES-East at Railroad Valley on day 213 at 22:00 UTC with surface reflectance assumed to be 0.1 .

\section{Inter-calibration of channel 1 images between the two satellites}

The joint use of GOES-West and GOES-East data implies their good relative calibration. In this work, GOES-11 for GOES-West and GOES-12 for GOES-East are used when they were both in operation for the cross-calibration analysis. To this end, the BRDF retrieved from GOES-West and GOES-East are compared at Boulder, Colorado in the period 1 March 2008 to 31 October 2008 in a $20 \times 20 \mathrm{~km}^{2}$ area around the site. Boulder $\left(105.006^{\circ} \mathrm{W}, 40^{\circ} \mathrm{N}\right)$ is located almost midway between the two satellites in terms of view geometry (less than $1 \mathrm{~km}$ ). Therefore, the retrieved BRDF from the two satellites are expected to be symmetric at about local noon (19:00 UTC). The BRDF retrieval algorithm, described in Sect. 4, was applied separately for single satellites so that the BRDF was derived for each satellite. Analysis showed that the derived BRDF changes little if AOD from AERONET was used for each time step. Next, the surface reflectance from GOES-West was compared against that from GOES-East if it is mirrored at 19:00 UTC. For example, the surface reflectance for GOES-West geometry at 18:00 UTC should be the same as the surface reflectance for GOES-East geometry at 20:00 UTC. Figure 13a shows the scatter plot of mirrored GOES-West vs. GOES-East surface reflectance retrievals. The surface reflectance from the two satellites are well correlated with $R=0.99$. The GOES-West surface reflectance is a little higher than that of GOES-East with a slope of 1.08. By trial and error, application of a gain factor of 0.95 to GOES-West TOA reflectance was found to correct the slope between the two retrieved BRDFs to 1.0, as shown in Fig. 13b. Therefore, to make use of GOESWest and GOES-East channel 1 radiances in the hybrid algorithm, a gain factor of 0.95 was applied to GOES-West TOA reflectance data. This conclusion also demonstrates that a calibration error of $5 \%$ can introduce an $8 \%$ difference in 

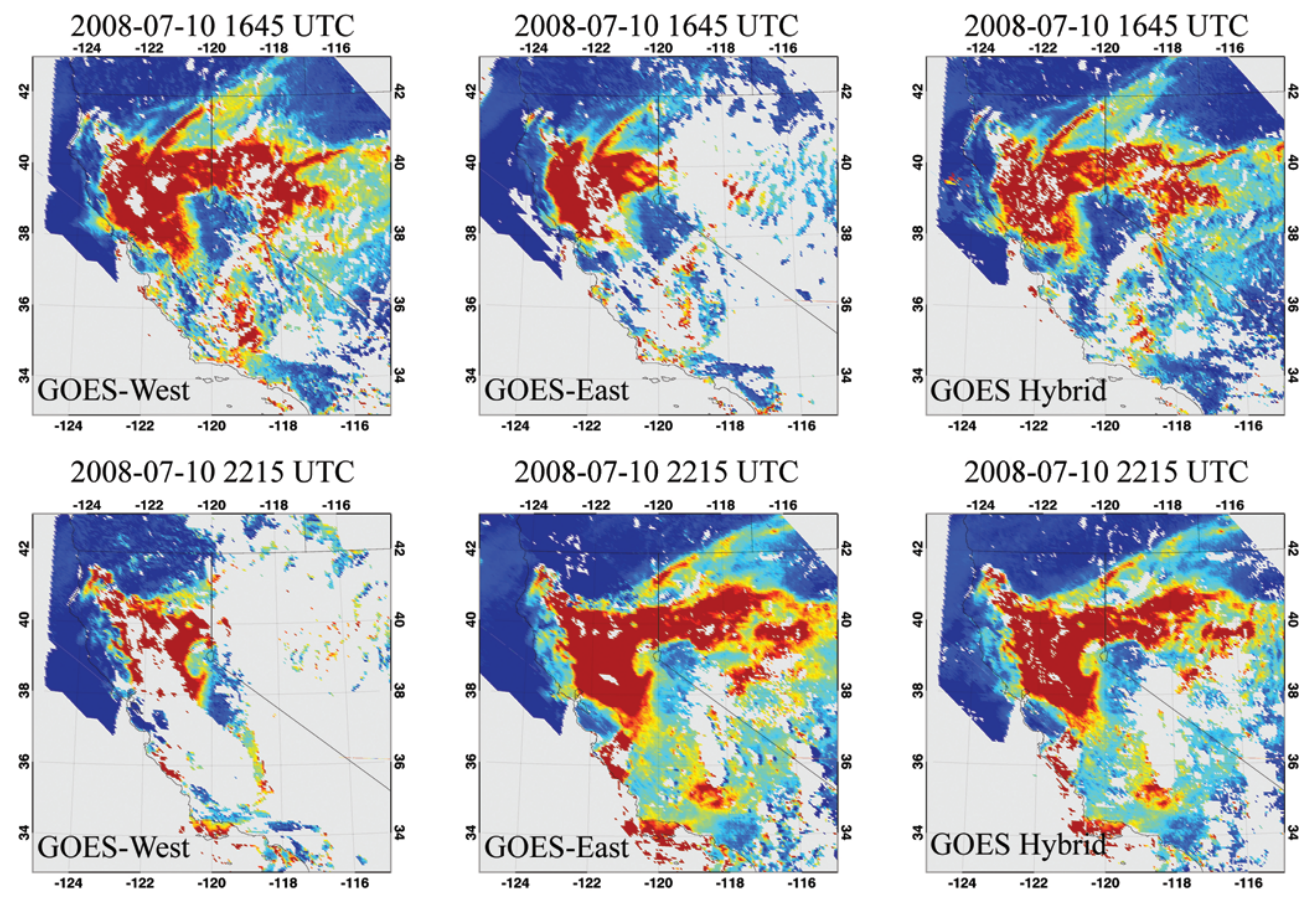

0.0

0.2

0.4

0.6

0.8

1.0

Fig. 12. Comparison of AOD retrievals from single satellite algorithms and from the hybrid algorithm for the California fire case on 10 July 2008 at two observation times: 16:45 UTC and 22:15 UTC. The retrievals from the combined algorithm are not plotted because they are the same as the single satellite retrievals with smaller scattering angles, i.e. GOES-West at 16:45 UTC and GOES-East at 22:15 UTC.
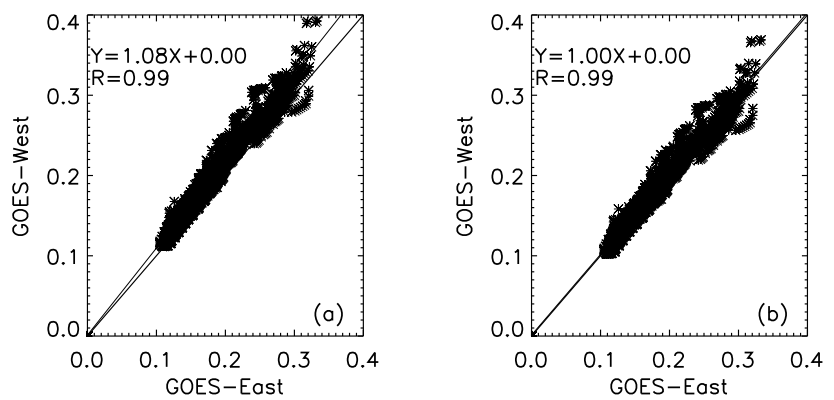

Fig. 13. (a) Scatter plot of GOES-West vs. GOES-East surface reflectance retrievals with mirror symmetry applied at Boulder. (b) Same as the left figure, but the GOES-West TOA reflectance is multiplied by a factor of 0.95 .

surface reflectance retrieval, which was used in the previous section for uncertainty analysis.

One potential error source in this analysis is a small eastward slope at about $0.22^{\circ}$ in the area around the Boulder AERONET site. The related uncertainty was estimated through perturbing the solar zenith angle and view zenith angle, calculating the perturbed surface reflectance using the retrieved BRDF, and comparing it with the original surface reflectance. This analysis showed that the uncertainty due

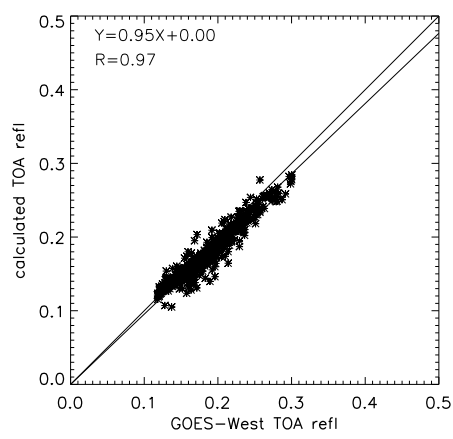

Fig. 14. Scatter plot between calculated TOA reflectance and GOES-West TOA reflectance.

to the slope of the surface is around $0.5 \%$, an order of magnitude less than the difference between GOES-West and GOES-East found above. Therefore, a small surface slope over the Boulder area does not introduce noticeable errors in the inter-calibration between the two satellites.

An alternative method can also be applied to inter-calibrate the two satellites' channel 1 radiances. In this method, BRDF was retrieved first using daily average AOD obtained from the GOES-MAIAC algorithm using GOES-East data, the same way as described above. Then, TOA reflectance in 
GOES-West geometry was calculated using the retrieved BRDF and daily average AOD. Lastly, the calculated and the measured TOA reflectance in GOES-West geometry were compared against each other. Figure 14 shows the scatter plot between the calculated TOA reflectance and GOESWest TOA reflectance. In this figure, several outliers have been removed, which are apparently due to the cloud/cloud shadow contaminations. The linear regression relation between them is $\rho_{\text {cal }}=0.95 \rho_{\text {GOES-West }}$, where the regression intercept is forced to be 0 , as the calculated TOA reflectance is expected to be 0 when GOES-West TOA reflectance is 0 . Therefore, both inter-calibration methods provide the same result.

Here, the GOES-East (GOES-12) is assumed to be more accurate and the TOA reflectance of GOES-West (GOES11 ) is corrected toward it. This is because GOES-12 was launched more than one year later than GOES-11 and GOES12 also has a longer period of star-based vicarious calibration sequence, i.e. GOES-12 has the sequence starting from 2003 while GOES-11 has the sequence starting from 2006 (NOAA GOES Calibration, 2011).

Similar inter-calibration between visible channels of the two GOES imagers was done by Nguyen et al. (2004). They compared the TOA reflectance observed from the two imagers along the $105^{\circ} \mathrm{W}$ line at noon, assuming the two satellites observed the same TOA reflectance at that time. The methods provided in this work can be used as alternative ways for inter-calibrating GOES-East and GOES-West.

\section{Conclusions}

In this study, a new "hybrid" AOD retrieval algorithm was developed over the western US utilizing both GOES-West and GOES-East satellite data. As far as the authors are aware, this is the first hybrid algorithm to use two satellites to retrieve AOD over a single location at a single time. In the new algorithm, daily average AOD in low AOD days (with AOD less than 0.3) is used to derive surface BRDF. The algorithm is based on two assumptions: AOD variation is small during days with small daily average AOD; surface BRDF shape is relatively stable and does not change much from day to day during short time intervals. Daily average AOD is derived from spatial and temporal averaging of the GOES-MAIAC AOD at geometries with good retrievals. With the BRDF shape known, and when both sensors observe the same area, the algorithm selects either GOES-East or GOES-West data with higher aerosol sensitivity for AOD retrieval and the other for surface reflectance retrieval. The aerosol sensitivity is related to the surface brightness, and is generally high for the low scattering angle geometries and poor at high angles. The complementary nature of GOES-East and GOES-West is used in this work to cross-calibrate the two sensors based on surface BRDF or TOA reflectance data. The algorithm is validated at three AERONET sites and the results compare to the AERONET AOD with correlation coefficients of 0.670.81 , the RMSEs of $0.06-0.07$, and more than $74 \%$ of AOD retrievals are within EE of $\pm(0.05+0.15 \tau)$. The use of both satellites significantly improves the AOD retrieval data coverage. Over the three sites, improvements are observed from $5 \%$ to $80 \%$ in number of coincidences with AERONET AOD. Such improvements in AOD retrieval coverage are also demonstrated in a regional retrieval example for a California fire case in 2008.

Several factors limit current GOES AOD retrieval. Current GOES only has one visible channel that can be used for aerosol retrieval, and therefore the algorithm does not have the degree of freedom to choose aerosol type. Less spectral channels in current GOES also limit its ability in cloud masking and therefore cloud contamination is expected to be higher than that in MODIS AOD retrievals. No onboard calibration also limits the accuracy of the measured TOA reflectance and further affects AOD retrieval accuracy. The next generation GOES-R series satellites will have spectral channels similar to MODIS for aerosol retrieval and cloud masking (Schmit et al., 2008). It is expected that the limitations with current GOES can be overcome when the new GOES-R series data are available.

Acknowledgements. This work is supported by GOES-R risk reduction program project \# NA11NES4400005. The authors would like to thank Yujie Wang for discussions and suggestions on the inter-calibration of GOES-West and GOES-East and would like to thank the two anonymous reviewers for the comments to improve the paper.

Edited by: M. Wendisch

\section{References}

Al-Saadi, J., Szykman, J., Pierce, R. B., Kittaka, C., Neil, D., Chu, D. A., Remer, L., Gumley, L., Prins, E., Weinstock, L., MacDonald, C., Wayland, R., Dimmick, F., and Fishman, J.: Improving National Air Quality Forecasts with Satellite Aerosol Observations, B. Am. Meteorol. Soc., 86, 1249-1261, doi:10.1175/BAMS-86-9-1249, 2005.

Anderson, T. L., Charlson, R. J., Winker, D. M., Ogren, J. A., and Holmen, K.: Mesoscale variations of tropospheric aerosols, J. Atmos. Sci., 60, 119-136, 2003.

ASPB and CIMSS Calibration Projects and Research: CIMSS GOES Activities, available at: http://cimss.ssec.wisc.edu/goes/ calibration/, (last access: 1 December 2011), 2011.

Charlson, R. J., Schwartz, S. E., Hales, J. M., Cess, R. D., Coakley, J. A., Hansen, J. E., and Hoffman, D. J.: Climate forcing by anthropogenesis aerosols, Science, 255, 423-430, 1992.

Chow, J. C., Watson, J. G., Mauderly, J. L., Costa, D. L., Wyzga, R. E., Vedal, S., Hidy, G. M., Altshuler, S. L., Marrack, D., Heuss, J. M., Wolff, G. T., Pope III, C. A., and Dockery, D. W.: Health Effects of Fine Particulate Air Pollution: Lines that Connect, Critical Review disscussion, J. Air Waste Manage. As., 56, 13681380, 2006. 
EUMETSAT: MSG-SEVIRI Rapid Scanning Service, available at: http://www.eumetsat.int/Home/Main/Satellites/ MeteosatSecondGeneration/Services/SP_20100628161215372 (last access: 14 January 2013), 2013.

GOES I-M databook: available at: http://goes.gsfc.nasa.gov/text/ goes.databook.html (last access: 9 June 2009), 1996.

Heidinger, A. K., Anne, V. R., and Dean, C.: Using MODIS to estimate cloud contamination of the AVHRR data record, J. Atmos. Ocean. Tech., 19, 586-601, 2001.

Hoff, R. and Christopher, S. A.: Remote Sensing of Particulate Matter Air Pollution from Space: Have we reached the promised land, J. Air Waste Manage. As., 59, 642-675, 2009.

Holben, B. N., Eck, T. F., Slutsker, I., Tanré, Buis, J. P., Setzer, A., Vermote, E., Reagan, J. A., Kaufman, Y. J., Nakajima, T., Lavenu, F., Jankowiak, I., and Smirnov, A.: AERONET: A federated instrument network and data archive for aerosol characterization, Remote Sens. Environ., 66, 1-16, 1998.

Intergovernmental Panel on Climate Change (IPCC): Climate Change 2007, The Physical Science Basis, Cambridge Univ. Press, Cambridge, UK, 2007.

Kaufman, Y. J., Tanré, D., Remer, L. A., Vermote, E., Chu, A., and Holben, B. N.: Operational remote sensing of tropospheric aerosol over land from EOS moderate resolution imaging spectroradiometer, J. Geophys. Res., 102, 17051-17067, 1997.

Kiehl, J. T. and Briegleb, B. P.: The radiative roles of sulfate aerosols and greenhouse gases in climate forcing, Science, 260, 311-314, 1993.

Knapp, K. R., Vonder Haar, T. H., and Kaufman, Y. J.: Aerosol optical depth retrieval from GOES-8: Uncertainty study and retrieval validation over South America, J. Geophys. Res., 107, 4055, doi:10.1029/2001JD000505, 2002.

Knapp, K. R., Frouin, F., Kondragunta, S., and Prados, A. I.: Towards aerosol optical depth retrievals over land from GOES visible radiances: Determining surface reflectance, Int. J. Remote Sens., 26, 4097-4116, 2005.

Levy, R. C., Remer, L. A., Mattoo, S., Vermote, E., and Kaufman, Y. J.: Second-generation operational algorithm: retrieval of aerosol properties over land from inversion of Moderate Resolution Imaging Spectroradiometer spectral reflectance, J. Geophys. Res., 112, D13211, doi:10.1029/2006JD007811, 2007.

Levy, R. C., Remer, L. A., Kleidman, R. G., Mattoo, S., Ichoku, C., Kahn, R., and Eck, T. F.: Global evaluation of the Collection 5 MODIS dark-target aerosol products over land, Atmos. Chem. Phys., 10, 10399-10420, doi:10.5194/acp-10-10399-2010, 2010.

Lohmann, U. and Feichter, J.: Global indirect aerosol effects: a review, Atmos. Chem. Phys., 5, 715-737, doi:10.5194/acp-5-7152005, 2005.

Lucht, W., Schaaf, C. B., and Strahler, A. H.: An Algorithm for the retrieval of albedo from space using semiempirical BRDF models, IEEE T. Geosci. Remote, 38, 977-998, 2000.

Lyapustin, A. and Knyazikhin, Y.: Green's function method in the radiative transfer problem. I: Homogeneous non-Lambertian surface, Appl. Optics, 50, 3495-3501, 2001.

Lyapustin, A. and Wang, Y.: Parameterized code Sharm-3D for radiative transfer over inhomogeneous surfaces, Appl. Optics, 55, 7602-7610, 2005.

Lyapustin, A. and Wang, Y.: MAIAC: multi-angle implementation of atmospheric correction for MODIS, algorithm theoretical basis document (ver. 1.0), 2008.
Lyapustin, A., Martonchik, J., Wang, Y., Laszlo, I., and Korkin, S.: Multiangle implementation of atmospheric correction (MAIAC): 1. Radiative transfer basis and look-up tables, J. Geophys. Res., 116, D03210, doi:10.1029/2010JD014985, 2011a.

Lyapustin, A., Wang, Y., Laszlo, I., Kahn, R., Korkin, S., Remer, L., Levy, R., and Reid, J. S.: Multiangle implementation of atmospheric correction (MAIAC): 2. Aerosol algorithm, J. Geophys. Res., 116, D03211, doi:10.1029/2010JD014986, 2011 b.

Maignan, F., Bréon, F.-M., and Lacaze, R.: Bidirectional reflectance of Earth targets: Evaluation of analytical models using a large set of spaceborne measurements with emphasis on the Hot spot, Remote Sens. Environ., 90, 210-220, 2004.

Nguyen, L., Doelling, D. R., Minnis, P., and Ayers, J. K.: Rapid technique to cross-calibrate satellite imager with visible channels, EarthObserving Systems IX, edited by: Barnes, W. L. and Butler, J. J., International Society for Optical Engineering, SPIE Proceedings, Vol. 5542, 227-235, 2004.

NOAA GOES Calibration site: available at: http://www.star.nesdis. noaa.gov/smcd/spb/fwu/homepage/GOES_star_cal.php (last access: 1 December 2011), 2011.

Pope III, C. A. and Dockery, D. W.: Health Effects of Fine Particulate Air Pollution: Lines that Connect, Critical Review, J. Air Waste Manage. As., 56, 709-742, 2006.

Popp, C., Hauser, A., Foppa, N., and Wunderle, S.: Remote sensing of aerosol optical depth over central Europe from MSG-SEVIRI data and accuracy assessment with ground-based AERONET measurements, 112, D24S11, doi:10.1029/2007JD008423, 2007.

Prados, A. I., Kondragunta, S., Ciren, P., and Knapp, K. R.: GOES Aerosol/Smoke Product (GASP) over North America: Comparisons to AERONET and MODIS observations, J. Geophys. Res., 112, D15201, doi:10.1029/2006JD007968, 2007.

Ramanathan, V., Crutzen, P. J., Kiehl, J. T., and Rosenfeld, D.: Aerosols, climate and the hydrological cycle, Science, 294, 2119-2124, 2001.

Roujean, J. L., Leroy, M., and Deschamps, P. Y.: A bidirectional reflectance model of the Earth's surface for the correction of remote sensing data, J. Geophys. Res., 97, 20455-20468, 1992.

Schaaf, C. B., Gao, F., Strahler, A. H., Lucht, W., Li, X., Tsang, T., Strugnell, N. C., Zhang, X., Jin, Y., Muller, J.-P., Lewis, P., Barnsley, M., Hobson, P., Disney, M., Roberts, G., Dunderdale, M., Doll, C., d'Entremont, R., Hu, B., Liang, S., and Privette, J. L.: First operational BRDF, albedo and nadir reflectance products from MODIS, Remote Sens. Environ., 83, 135-148, 2002.

Schmit, T. J., Li, J., Gurka, J. J., Goldberg, M. D., Schrab, K. J., Li, J., and Feltz, W. F.: The GOES-R Advanced Baseline Imager and the continuation of current sounder products, J. Appl. Meteor Clim., 47, 2696-2711, doi:10.1175/2008JAMC1858.1, 2008.

Smirnov, A., Holben, B. N., Eck, T. F., Slutsker, I., Chatenet, B., and Pinker, R. T.: Diurnal variability of aerosol optical depth observed at AERONET (Aerosol Robotic Network) sites, Geophys. Res. Lett. , 29, 2115, doi:10.1029/2002GL016305, 2002.

Stowe, L. L., Davis, P. A., and McClain, E. P.: Scientific basis and initial evaluation of CLAVR-1 global clear/cloud classification algorithm for the advanced very high resolution radiometer, J. Atmos. Ocean. Tech., 16, 656-681, 1999.

Vermote, E. F. and Kotchenova, S.: Atmospheric correction for the monitoring of land surfaces, J. Geophys. Res., 113, D23S90, doi:10.1029/2007JD009662, 2008. 
Weinreb, M. P., Jamison, M., Fulton, N., Chen, Y., Johnson, J. X., Bremer, J., Smith, C., and Baucom, J.: Operational calibration of Geostationary Operational Environmental Satellite-8 and -9 imagers and sounders, Appl. Optics, 36, 6895-6904, 1997.

Wang, Y., Lyapustin, A., Privette, J., Cook, R., SanthanaVannan, S. K., Vermote, E., and Schaaf, C.: Assessment of Biases in MODIS Surface Reflectance Due to Lambertian Approximation, Remote Sens. Environ., 114, 2791-2801, doi:10.1016/j.rse.2010.06.013, 2010.

Zhang, H., Hoff, R. M., McCann, K., Ciren, P., Kondragunta, S., and Prados, A.: Influence of the ozone and water vapor on the GOES Aerosol and Smoke Product (GASP) retrieval, NOAA Technical report NESDIS 128, 2008.
Zhang, H., Hoff, R. M., and Kondragunta, S.: Development of IDEA product for GOES-R aerosol data, Proc. SPIE, 7456, 74560O, doi:10.1117/12.828095, 2009.

Zhang, H., Lyapustin, A., Wang, Y., Kondragunta, S., Laszlo, I., Ciren, P., and Hoff, R. M.: A multi-angle aerosol optical depth retrieval algorithm for geostationary satellite data over the United States, Atmos. Chem. Phys., 11, 11977-11991, doi:10.5194/acp11-11977-2011, 2011. 